\title{
Apicificação de um Dente Avulsionado Utilizando MTA: Relato de Caso
} MTA Apexification of an Avulsed Tooth: Case Report

\author{
Nino Velho de Mesquita ${ }^{1}$, Marcus Vinícius Reis Só ${ }^{2}$, Ricardo Abreu da Rosa ${ }^{3}$, Aline Martins Justo ${ }^{4}$, Regis Burmeister dos Santos ${ }^{5}$
}

\section{Abstract}

The objective of this case report was to demonstrate the performance of apexification using a MTA plug $(3 \mathrm{~mm})$ in a re-implanted upper central incisor. The treatment was performed in three visits with the use of calcium hydroxide paste as intracanal medicament for 14 days. The final treatment radiograph shows no MTA overflow. The six months follow-up radiograph showed the healing of the periapical tissues and absence of resorption signals.

Key-words: Endodontics. Avulsion. Replantation. Apexification. Calcium hydroxide. MTA.

\section{Resumo}

O objetivo do relato deste caso clínico foi demonstrar a realização de uma apicificação, através de um plug de MTA $(3 \mathrm{~mm})$, em um incisivo central superior reimplantado. O tratamento foi realizado em três consultas com utilização da pasta de hidróxido de cálcio como medicação intracanal por 14 dias. A radiografia periapical final do tratamento não mostra extravasamento de MTA. A radiografia de controle, após seis meses, demonstrou cicatrização dos tecidos periapicais e ausência de sinais radiográficos de reabsorção.

Palavras-chave: Endodontia. Avulsão. Reimplante. Apicificação. Hidróxido de cálcio. MTA.

\section{Introdução}

O fenômeno que assinala o início da formação radicular é o surgimento da bainha epitelial de Hertwig. Essa bainha de células epiteliais prolifera em torno da papila dentária, induzindo a diferenciação das células superficiais em odontoblastos, formando a dentina radicular. No processo de formação da raiz, na região mais cervical dessa bainha, ocorre uma degeneração contínua das células que compõem a bainha epitelial de Hertwig, provocando soluções de continuidade e permitindo a migração dos cementoblastos para junto da superfície externa da dentina, onde iniciam a cementogênese (FARACO JÚNIOR; TOVO, 2007).

Quando ocorre a necrose pulpar, a formação radicular cessa e ocorre uma condição anatômica desfavorável para a realização do tratamento endodôntico, pois as paredes radiculares se apresentam finas e frágeis, com abertura apical de diâmetro maior que o diâmetro do canal radicular. Essas características, além de impedir a realização do preparo biomecânico, interferem na fase de obturação, pois não permitem a formação do batente apical para o assentamento do cone guta-percha principal (SILVA; LEONARDO; UTRILLA, 1991).
1 Cirurgião-dentista, Faculdade de Odontologia, Universidade Federal do Rio Grande do Sul, Porto Alegre, RS, Brasil.

2 Professor Adjunto de Endodontia, Faculdade de Odontologia, Universidade Federal do Rio Grande do Sul, Porto Alegre, RS, Brasil.

3 Doutorando do Programa de Pós-Graduação Strito Senso da Faculdade de Odontologia, Departamento de Odontologia Conservadora, Universidade Federal do Rio Grande do Sul, Porto Alegre, RS, Brasil.

4 Mestranda em Clínica Odontológica, área de concentração em Endodontia, Faculdade de Odontologia, Universidade Federal do Rio Grande do Sul, Porto Alegre, RS, Brasil.

${ }^{5}$ Professor Titular de Endodontia, Faculdade de Odontologia, Universidade Federal do Rio Grande do Sul, Porto Alegre, RS, Brasil.

Correspondência: Dr. Marcus Vinícius Reis Só

Endereço: Rua Souza Lobo, 62/03 - CEP 91320-320, Porto Alegre - RS, Brasi Fone: (51) 99678504

E-mail: endo-so@hotmail.com

Data de Submissão: 29/03/2010

Data de Aceite: 08/04/2010

Em dentes permanentes com rizogênese incompleta e necrose pulpar, a terapia endodôntica requer cuidados especiais que se tornam mais exigentes frente a uma avulsão traumática. Nestes casos, a terapia consiste em estimular a continuação do desenvolvimento radicular por meio do uso de substâncias biocompatíveis, tendo, como objetivo, criar condições favoráveis para que ocorra o fechamento da abertura apical, pela deposição de tecido mineralizado. O fechamento apical permite a realização do preparo biomecânico e a obturação do canal de forma definitiva (SOARES; GOLDBERG, 2001).

A despeito das altas taxas de sucesso obtidas com a formação de barreira de tecido mineralizado, por meio do emprego da pasta de hidróxido de cálcio, o longo tempo de tratamento aliado à possibilidade de reinfecção e enfraquecimento radicular (CHHABRA; SINGBAL; KAMAT, 2010) têm motivado a busca por outros materiais biocompatíveis e que possibilitem a execução do tratamento em uma ou duas sessões (EL MELIGY; AVERY, 2006; SIMON et al., 2007). Sendo assim, o emprego do agregado trióxido mineral (MTA) tem sido sugerido como uma modalidade de tratamento para dentes com ápices imaturos e necrose pulpar.

O MTA tem se destacado por sua biocompatibilidade, por não possuir potencial carcinogênico ou mutagênico (KETTERING; TORABINEJAD, 1995), por estimular a neoformação dentinária e por promover selamento adequado, prevenindo microinfiltração (LEE; MONSEF; TORABINEJAD, 1993). Supera, desta forma, as principais deficiências do hidróxido de cálcio, quais sejam a solubilidade e a falta de resistência mecânica. O MTA é um pó de coloração cinza ou branca, com finas partículas hidrofílicas, composto principalmente por silicato tricálcio, silicato dicálcio, aluminato tricálcio, alumino-ferrítico tetracálcio, sulfato de cálcio diidratado e óxido de bismuto. É resistente à compressão e tem um tempo de presa em torno de 2 horas e 45 minutos (FARACO JÚNIOR; HOLLAND, 2004). A formação de depósitos do tipo apatita, durante o processo de maturação do MTA, promove o preenchimento de gaps durante a fase de contração do material, melhorando a resistência friccional do MTA às paredes do canal radicular (CHHABRA; SINGBAL; KAMAT, 
2010). Além disso, o MTA favorece o processo de apicificação e cicatrização apical (FELIPPE; FELIPPE; ROCHA, 2006).

$O$ objetivo do relato deste caso é relatar o tratamento de um incisivo central superior, em três sessões, com o uso do MTA, visando a apicificação.

\section{Relato do Caso}

Paciente F.P.S., 10 anos, gênero masculino, foi encaminhado para atendimento no Curso de Especialização em Endodontia da Faculdade de Odontologia da Universidade Federal do Rio Grande do Sul (UFRGS) para realização de tratamento endodôntico no elemento 11. Conforme relato da mãe, oito dias antes, a criança sofrera avulsão do referido dente e subluxação do elemento 21 durante a realização de prática esportiva. Conforme o boletim de atendimento do Hospital de Pronto Socorro Municipal de Porto Alegre, onde foi realizado o atendimento de urgência no dia do trauma, o reimplante aconteceu até uma hora após a lesão traumática. Segundo o familiar, o elemento 11 teve a coroa e a raiz limpa com escova dental e permaneceu em água de abastecimento público até o momento da consulta de urgência. Durante o pronto atendimento, foi realizada contenção semi-rígida com fio ortodôntico flexível e resina composta, estendendo-se do elemento 13 ao 23 . O paciente fez uso do antibióticoterapia (amoxicilina $250 \mathrm{mg} / 5 \mathrm{ml}$; Infabra Ind. Farm. Bras. Ltda, RJ, Brasil), de seis em seis horas, durante sete dias, visando o controle da contaminação da superfície radicular e do interior do alvéolo.

A primeira consulta do paciente na Faculdade de Odontologia da UFRGS foi realizada oito dias após o acidente. O teste de sensibilidade pulpar apresentou resposta negativa para os elementos 11,21 e 22 . Ao teste de pressão e percussão, a resposta foi positiva nesses elementos. Em termos de manifestação objetiva, o paciente não apresentou edema, fístula ou alteração cromática no elemento envolvido. $\mathrm{Na}$ radiografia periapical, foi observada a rizogênese incompleta dos elementos envolvidos (Figura 1).

Durante esta consulta, foi realizado o isolamento absoluto, abertura coronária e sanificação do canal radicular com solução de hipoclorito de sódio ( $\mathrm{NaOCl}$ ) 2,5\% (Farmácia Calêndula, Porto Alegre, $\mathrm{RS}$, Brasil). Inicialmente foi realizada radiografia odontométrica para determinar o comprimento de trabalho $(20 \mathrm{~mm})$ (Figura 2). O conduto foi instrumentado com instrumentos tipo $\mathrm{K}$ manualmente até a lima \#80 (Dentsply-Maillefer, Ballaigues, Switzerland). Posteriormente, o canal radicular foi preenchido com EDTA 17\% (Farmácia Calêndula, Porto Alegre, RS, Brasil) e agitado com lima tipo K \#50 (DentsplyMaillefer, Ballaigues, Switzerland) durante dois minutos. A seguir, o canal novamente irrigado com $\mathrm{NaOCl} 2,5 \%$, seco com cones de papel absorvente (Dentsply, Petrópolis, RJ, Brasil) e preenchido com a pasta à base de hidróxido de cálcio (Calen, SS White, São Paulo, Brasil). O selamento coronário foi realizado com material à base de ionômero de vidro (Vitrofil, DFL, Jacarepaguá, RJ, Brasil).

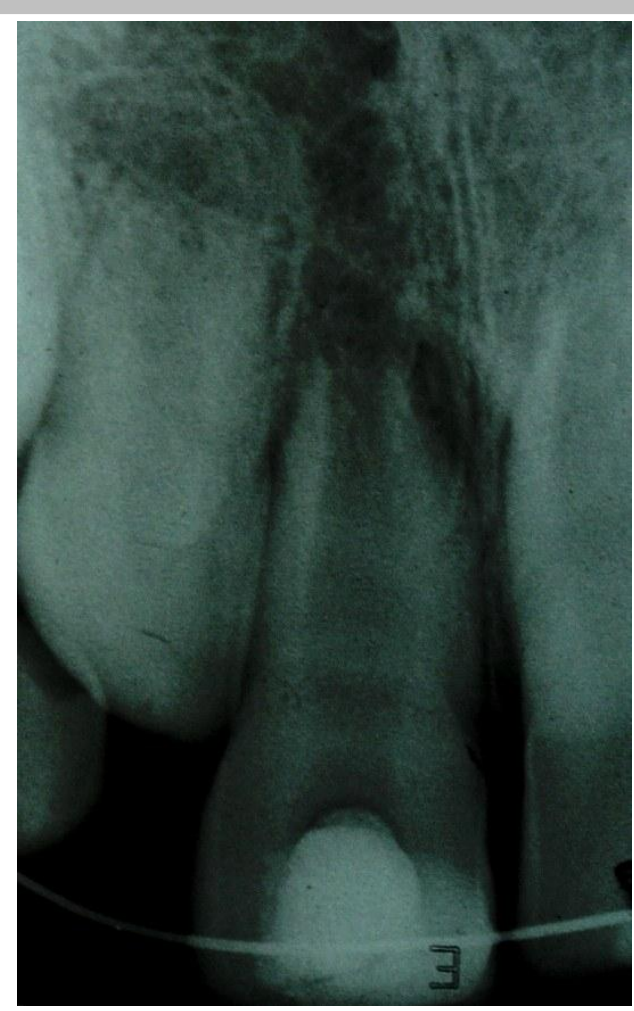

Figura 1 - Radiografia periapical inicial.

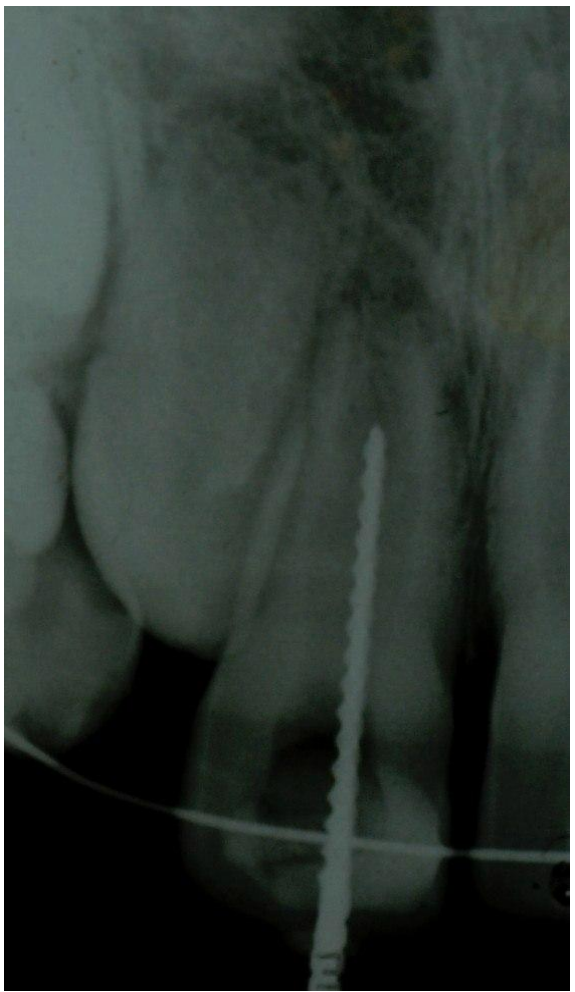

Figura 2 - Radiografia periapical odontométrica do elemento 11. 
Quatorze dias após, foi retirada a contenção, feito o isolamento absoluto e o curativo de demora foi removido sob copiosa irrigação de hipoclorito de sódio 2,5\% (Farmácia Calêndula, Porto Alegre, RS, Brasil). A secagem do canal radicular foi realizada com pontas de papel absorvente de calibre \#80 (Dentsply, Petrópolis, RJ, Brasil). Na sequência, foi preparado o MTA (Angelus, Londrina, PR, Brasil), conforme especificações do fabricante, levado ao canal radicular em pequenas porções através de um porta MTA (Angelus, Londrina, PR, Brasil) e condensado com um calcador de Paiva número 3 até a obtenção de um plug apical de $3 \mathrm{~mm}$, visualizado através de uma radiografia periapical (Figuras 3). Após, o canal foi preenchido com pasta à base de hidróxido da cálcio (Calen; SS White, São Paulo, Brasil) e selado com ionômero de vidro (Vitrofil; DFL, Jacarepaguá, RJ, Brasil).

Quatorze dias depois, a obturação do terço médio e cervical do canal radicular foi realizada utilizando guta-percha (Dentsply, Petrópolis, RJ, Brasil) e cimento Sealer 26 (Dentsply, Petrópolis, RJ, Brasil) através da termocompactação da guta-percha com gutta condensors \#80 (Dentsply-Maillefer, Ballaigues, Switzerland). Seguiu a realização de uma radiografia periapical final e a restauração da cavidade com ionômero de vidro (Vitrofil, DFL, Jacarepaguá, RJ, Brasil) (Figura 4). Quarenta e cinco dias após o trauma foram realizados novos testes de sensibilidade nos elementos 21 e 22, com resultado positivo para ambos. Conforme Lopes e Siqueira Júnior (2010), nos casos de lesão traumática, os dentes podem não apresentar sensibilidade frente a testes térmicos por vários dias ou semanas após o traumatismo, mesmo havendo presença de tecido vital na porção terminal do canal radicular. Seis meses mais tarde, o paciente retornou para o controle clínico com ausência de sinais e sintomas de patologia periapical e radiograficamente evidenciando presença de lâmina dura (Figura 5).

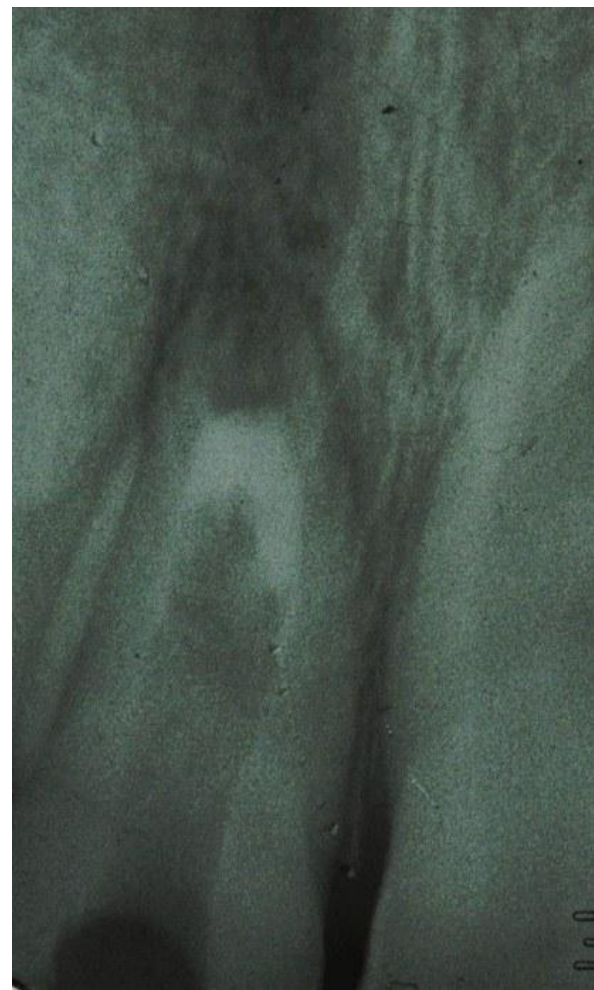

Figura 3 - Radiografia periapical com a presença do plug de MTA no elemento 1.

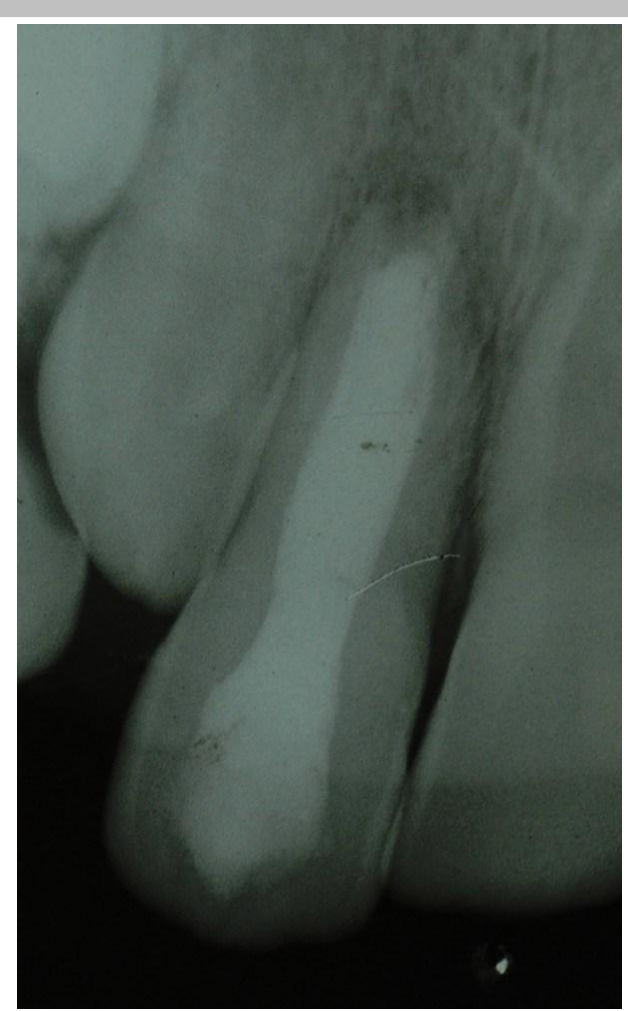

Figura 4 - Radiografia periapical do elemento 11 após obturação do canal.

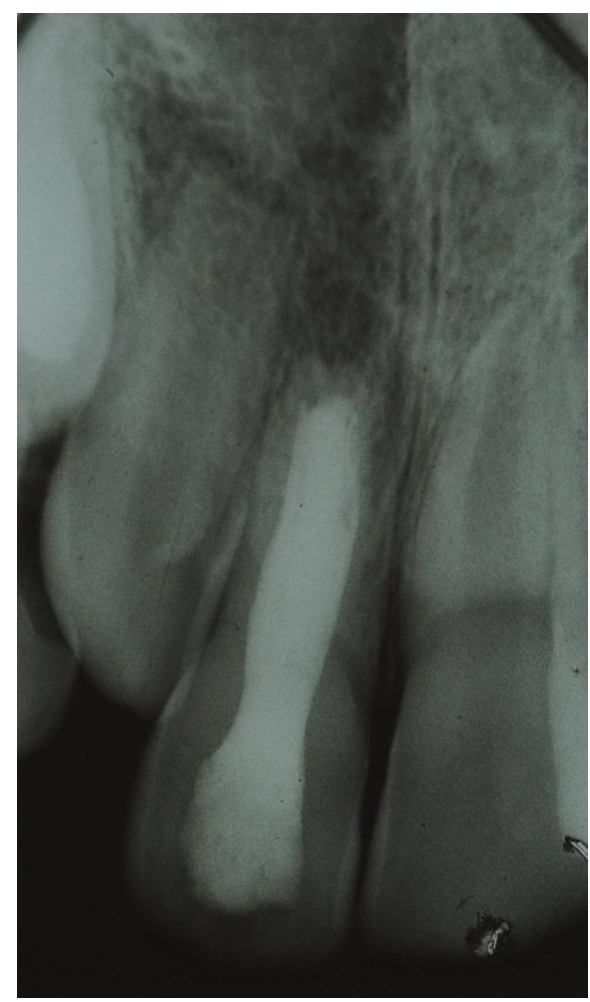

Figura 5 - Radiografia periapical do elemento 11 após seis meses da conclusão do caso. 


\section{Discussão}

A apicificação é o tratamento realizado em dentes permanentes jovens, com necrose pulpar, para induzir o fechamento apical através da estimulação da formação de um tecido mineralizado, com o propósito de complementar o desenvolvimento da raiz dental e permitir a obturação do canal radicular.

São empregadas substâncias que induzam à formação de uma barreira de tecido mineralizado, impedindo o extravasamento do material obturador. O hidróxido de cálcio e o MTA são as substâncias apicificadoras de escolha devido a sua compatibilidade biológica, propriedades bactericidas e indutoras de mineralização (LOPES; SIQUEIRA JÚNIOR, 2010).

Em relação ao caso clínico apresentado, é importante tecer algumas considerações referentes à utilização do curativo com hidróxido de cálcio, à escolha pelo o MTA, bem como ao prognóstico para o tratamento realizado. Embora Felippe, Felippe e Rocha (2006) tenham demonstrado que a utilização prévia do curativo de hidróxido de cálcio tenha facilitado maior extravasamento de MTA, optamos pelo curativo de demora com aquela substância por 14 dias, para realçar o controle da infecção intracanal e não percebemos posterior extravasamento do cimento MTA.

Cumpre salientar que a opção pelo tratamento em três consultas foi feita pela impossibilidade de o paciente retornar para as trocas de curativo, bem como para os devidos controles. Muitos estudos têm demonstrado que o MTA é um material biocompatível, com capacidade osteoindutora capaz de promover um selamento marginal adequado e apresentar efeito antimicrobiano (HOLLAND et al., 2001; LEE; MONSEF; TORABINEJAD, 1993).

Hachmeister et al. (2002) demonstraram que, no tratamento de dentes despolpados imaturos, o prognóstico mais favorável ocorre com a apicificação estimulada pelo MTA, o qual apresentou maior resistência ao deslocamento com uma espessura de $4 \mathrm{~mm}$ quando comparado a de $1 \mathrm{~mm}$.

Fatores como período de tempo em que o dente se manteve fora do alvéolo e forma de armazenamento são determinantes para o prognóstico do dente que sofreu uma avulsão dentária (FLORES et al., 2007). Neste caso clínico, o dente foi reimplantado aproximadamente uma hora após a avulsão. Este tempo seria considerado aceitável se não fosse $o$ fato de que a forma de armazenamento em água e a limpeza do dente com escova foram realizadas. É passível de se acreditar que uma reabsorção por substituição seja a sequela mais previsível, uma vez que a probabilidade de manutenção da viabilidade das células do ligamento periodontal não tenha ocorrido (FUSS; TSESIS; LIN, 2003; NE; WHITERSPOON; GUTMANN, 1999).

Além disso, a apicificação foi realizada com o objetivo de preservar o elemento dental de uma criança de 10 anos de idade pelo maior tempo possível. Esta manobra objetiva proporcionar adequadas condições para o desenvolvimento psicossocial da criança, com vistas ao desenvolvimento dela, uma vez que a ausência de um dente anterior poderia trazer consequências à sua auto-estima e relacionamento interpessoal. Soma-se a isso a necessidade de manutenção do tecido ósseo para uma resolução definitiva futura.

\section{Considerações Finais}

Este caso clínico visou à possibilidade de realização de uma apicificação, em três consultas, em um dente avulsionado. Embora o período de proservação seja pequeno e o prognóstico sombrio, foi possível verificar a abreviação do tempo de tratamento e a constatação de que este é um procedimento com probabilidade de sucesso.
A opção pelo método executado não tem por princípio substituir o tratamento convencional, com trocas de pasta à base de hidróxido de cálcio, mas sim buscar mais uma alternativa no tratamento de dentes com rizogênese incompleta.

\section{Referências}

CHHABRA, N.; SINGBAL, K.P.; KAMAT, S. Successful apexification with resolution of the periapical lesion using mineral trioxide aggregate and demineralized freeze-dried bone allograft. J. Conserv. Dent., Amritsar, Índia, v. 13, no. 10, p. 106-109, Apr. 2010.

EL MELIGY, O.A.; AVERY, D.R. Comparison of apexification with mineral trioxide aggregate and calcium hydroxide. Pediatr. Dent., Chicago, v. 28, no. 3, p. 248-253, May/June 2006.

FARACO JÚNIOR, I.M.; HOLLAND, R. Histomorphological response of dogs' dental pulp capped with white mineral trioxide aggregate. Braz. Dent. J., São Paulo, v. 15, no. 2, p. 104-108, 2004.

FARACO JÚNIOR, I.M.; TOVO, M.F. Inter-relação endodontiaodontopediatria. In: SÓ, M. V. R. Endodontia: as interfaces no contexto da Odontologia. São Paulo: Liv. Santos, 2007. Cap. 10, p. 291-304.

FELIPPE, W.T.; FELIPPE, M.C.S.; ROCHA, M.J.C. The effect of mineral trioxide aggregate on the apexification and periapical healing of teeth with incomplete root formation. Int. Endod. J., Oxford, v. 39, no. 1, p. 2-9, Jan. 2006.

FLORES, M.T. et al. Guidelines of the management of traumatic dental injuries. II. Avulsion of permanent teeth. Dent. Traumatol., Copenhagen, v. 23, no. 3, p. 130-136, June 2007.

FUSS, Z.; TSESIS, I.; LIN, S. Root resorption - diagnosis, classification and treatment choices based on stimulation factors. Dent. Traumatol., Copenhagen, v. 19, no. 4, p. 175-182, Aug. 2003.

HACHMEISTER, D.R. et al. The sealing ability and retention characteristics of mineral trioxide aggregate in a model of apexification. J. Endod., Chicago, v. 28, no. 5, p. 386-390, May 2002.

HOLLAND, R. et al. Mineral trioxide aggregate repair of lateral root perforations. J. Endod., Chicago, v. 27, no. 4, p. 281-284, Apr. 2001.

KETTERING, J.D.; TORABINEJAD, M. Investigation of mutagenicity of mineral trioxide aggregate and other commonly used root-end filling materials. J. Endod., Chicago, v. 21, no. 11, p. 537-542, Nov. 1995.

LEE, S.J.; MONSEF, M.; TORABINEJAD, M. Sealing ability of a mineral trioxide aggregate for re air of lateral root perforations. J. Endod., Chicago, v. 19, no. 11, p. 541-544, Nov. 1993.

LOPES, H.P.; SIQUEIRA JÚNIOR, J.F. Endodontia: biologia e técnica. 34. ed. Rio de Janeiro: Guanabara Koogan, 2010. Cap. 24, p. 877-890.

NE, R.F.; WHITERSPOON, D.E.; GUTMANN, J.L. Tooth resorption. Buintessence Int., Berlin, v. 30, no. 1, p. 9-25, Jan. 1999.

SILVA, L.A.B.; LEONARDO, M.R.; UTRILLA, L.S. Rizogênese incompleta: efeitos de diferentes pastas à base de hidróxido de cálcio na complementação radicular e na reparação periapical em dentes de 
cães - estudo histológico. Rev. Odontol. Univ. São Paulo, Bauru, v. 5, n. 1, p. 29-36, jan./jun. 1991.

SIMON, S. et al. The use of mineral trioxide aggregate in one-visit apexification treatment: a prospective study. Int. Endod. J., Oxford, v. 40, no. 3, p. 186-197, Mar. 2007.

SOARES, I.J.; GOLDBERG, F. Endodontia: técnica e fundamentos. Porto Alegre: Artmed, 2001. Cap. 13, p. 251-262.

Rev. Fac. Odontol. Porto Alegre, v. 52, n. 1/3, p. 67-71, jan./dez., 2011. 